\section{Expression of hyaluronan synthase 3 in deformed human temporomandibular joint discs: in vivo and in vitro studies}

\author{
T. Matsumoto, M. Inayama, I. Tojyo, \\ N. Kiga, S. Fujita \\ Department of Oral and Maxillofacial \\ Surgery, Wakayama Medical University, \\ Japan
}

\section{Abstract}

The present study aimed at investigating the expression of a hyaluronan synthase (HAS) 3 in tissue samples of deformed human temporomandibular joint (TMJ) discs and cells obtained from the discs. Fifteen adult human TMJ discs (twelve diseased discs and three normal discs) were used in this study. The twelve diseased discs were obtained from twelve patients with internal derangement (ID) of TMJ. These patients all had anteriorly displaced discs and deformed discs. The tissues were immunohistochemically stained using HAS3 antibodies. In addition, the subcultured TMJ disc cells under both normal and hypoxic conditions $\left(\mathrm{O}_{2}: 2 \%\right)$ were incubated for $3,6,12$, and $24 \mathrm{~h}$ after addition of interleukin$1 \beta$ (IL-1 $\beta)(1 \mathrm{ng} / \mathrm{mL})$. Subsequently, the expression of HAS3 was examined using realtime reverse transcription-polymerase chain reaction (RT-PCR). The control group showed from negative to weak positive reactions for HAS3 on immunohistochemical staining. The discs extracted from twelve cases with ID presented from moderate to strong positive reactions for HAS3. The quantity of HAS3 mRNA was compared with a control group, and showed a 204-fold increase at $3 \mathrm{~h}$, a 26 -fold increase at $6 \mathrm{~h}, \mathrm{a} 2.5$-fold increase at $12 \mathrm{~h}$ and a 32 -fold increase at $24 \mathrm{~h}$ under hypoxia with the addition of IL-1 $\beta$. The expression of HAS3 mRNA was significantly enhanced at $3 \mathrm{~h}$ and $24 \mathrm{~h}$. The results obtained suggest that HAS3 is related to the pathological changes of human TMJ discs affected by ID.

\section{Introduction}

Extracellular matrix (ECM) is important for physiological phenomenon such as generation and differentiation, progression of pathological condition (e.g. inflammation, tumor), and scaffold such as healing and regeneration. Temporomandibular joint internal derangement (TMJ ID) involves an altered anatomical relationship of the disc-condyle complex and it is likely to lead histopathological changes that culminate in tissue degeneration as occurs in disc displacement TMJ discs. ${ }^{1}$ In TMJ ID, it has been suggested that pathological changes have a potential in collagen and the proteoglycan constituted ECM.,3

Hyaluronan (HA) is a non-sulphated glycosaminoglycan (GAG), which is widely distributed in the extracellular matrix (ECM). ${ }^{4}$ $\mathrm{HA}$ is involved in a variety of biological processes, such as maintenance of tissue architecture, cell proliferation, migration, differentiation, angiogenesis, wound healing and tumourigenesis. ${ }^{5}$ HA is synthesized by hyaluronan synthases (HASs) located at the plasma membrane of cells. ${ }^{6}$ Three isoforms of HAS have been shown to be responsible for the synthesis and regulation of different molecular weight HA: HAS1 and HAS2 polymerised high molecular weight HA, whereas HAS3 generates low molecular weight HA. ${ }^{7}$ In articular cartilage, HAS2 is dominantly presented, by contrast, the expression of HAS3 is up-regulation in pathological conditions. ${ }^{8}$ Furthermore, the expression of HAS3 in temporomandibular joint disc has never been examined. Histochemical studies of human TMJ disc with ID without reduction have dealt mainly with some aspects of pathologic changes of the ECM and lack of a broader vision of disc morphologic features and cell change after anterior disc displacement. ${ }^{3}$ The development of arthroscopy for small joints such as the TMJ has revealed that various inflammatory reactions with immune responses occur during the pathological process of TMJ ID. ${ }^{9,10}$ Although the pathophysiology of TMJ ID is not fully understood, three mechanisms, including direct mechanical injury, hypoxia-reperfusion injury, and neurogenic inflammation have so far been considered. ${ }^{11}$ Hypoxia-reperfusion injury could be caused by a transient overcoming of the hydrostatic pressure in the intracapsular space in the TMJ by the end-capillary perfusion pressure of intracapsular tissues during pathological mechanical stress (e.g. clenching).${ }^{12} \mathrm{~A}$ variety of cytokines were detected in synovial fluid from patients with ID or osteoarthritis (OA) in the TMJ. ${ }^{13-16}$ In particular, interleukin-1 $\beta$ (IL-1 $\beta$ ) appeared to be the pivotal agent in the network of proinflammatory cytokines, mediating a variety of host defense processes, including inflammation and cellular responses to injury involved in joint destruction. ${ }^{17}$

In this study, we performed an experiment using human TMJ disc tissues to determine whether HAS3 was related to the pathological changes of TMJ discs with ID. In addition, we examined the expression of HAS3 in cultured human TMJ disc cells treated with hypoxia and IL-1 $\beta$.
Correspondence: T. Matsumoto, Department of Oral and Maxillofacial Surgery, Wakayama, Medical University. 811-1, Kimiidera, Wakayama-city 641-8509, Japan.

Tel. +81.73.441.0643 - Fax: +81.73.441.0643.

E-mail:mash2@mua.biglobe.ne.jp

Key words: temporomandibular joint disc, internal derangement, hyaluronan synthase 3 (HAS3), human, hypoxia.

Acknowledgements: this research was supported in part by a grant-in-aid for Scientific Research from the Japanese Ministry of Education, Science, Sports and Culture (No.17791479).

Received for publication: 14 September 2010. Accepted for publication: 15 November 2010.

This work is licensed under a Creative Commons Attribution 3.0 License (by-nc 3.0).

(O) Copyright T. Matsumoto et al., 2010

Licensee PAGEPress, Italy

European Journal of Histochemistry 2010; 54:e50 doi:10.4081/ejh.2010.e50

\section{Materials and Methods}

\section{Reagents}

Non-GM0 human IL-1 $\beta$ was purchased from PeproTech (London, UK).

\section{Tissues}

Fifteen TMJ discs were investigated (Table 1). All patients gave complete informed consent for the surgery and the use of their tissue in the research, which was approved by the Human Research Ethics Committee, Wakayama Medical University, Wakayama, Japan. Three control specimens were obtained from autopsies. The patients were 48,61 and 70 years of age, with no clinical history of TMJ pathology. Twelve TMJ discs were obtained from twelve patients (ten females and two males) because of ID with severe pain and dysfunction. The ages of the patients ranged from 24 to 72 years, with a mean age of 49.6 years. Magnetic resonance imaging revealed that all patients had anterior disc displacement without reduction. Indication criteria for open surgery of the TMJ ID were: i) unsuccessful conservative therapy; ii) persistent TMJ pain and dysfunction; iii) unsuccessful arthrocentesis and arthroscopic surgery. All discs excised during surgery were macroscopically deformed, and none of the discs had a normal biconcave shape. Furthermore, we evaluated the degree of TMJ disc degeneration by using a histopathological grading score system. ${ }^{18}$ 


\section{Cultivation of temporomandibular joint disc cells}

TMJ disc cells were prepared according to the method of previously reported. ${ }^{19}$ For the experiments, we used the cells from the sixth to twelfth passages. The cells were plated at a density of $1 \times 10^{6}$ well in 6 -well plates (Iwaki, Asahi Techno Glass, Funabashi, Japan) in a medium containing 10\% FBS. The following day, the medium was changed to a serum-free medium and the cells were incubated for $24 \mathrm{~h}$. The culture plates were rinsed with phosphate buffered saline (PBS), and $2 \mathrm{~mL}$ of fresh serum-free medium with or without $1 \mathrm{ng} / \mathrm{mL}$ of IL-1 $\beta$. The experiment was performed for $3,6,12$, and $24 \mathrm{~h}$ in a humidified atmosphere of normoxic conditions $\left(20 \% \mathrm{O}_{2}\right.$, $5 \% \mathrm{CO}_{2}$, and $75 \% \mathrm{~N}_{2}$ ), or hypoxic conditions $\left(2 \% \mathrm{O}_{2}, 5 \% \mathrm{CO}_{2}\right.$, and $93 \% \mathrm{~N}_{2}$ ) by $\mathrm{N}_{2}-\mathrm{O}_{2}-\mathrm{CO}_{2}$ incubator (ESPEC Corp., Osaka, Japan). Three independent experiments involving separate cell capture were performed.

\section{Immunohistochemistry}

All specimens were cut sagittally, and immediately fixed in PBS solution containing 4\% paraformaldehyde. These sections were prepared as conventional paraffin-embedded specimens. Specimens were sliced $5 \mu$ m thick. The sections were placed in $0.3 \%$ hydrogen peroxide and methanol for $30 \mathrm{~min}$ to block endogenous peroxidase, and then incubated for $30 \mathrm{~min}$ at room temperature with $3 \%$ skim milk to block nonspecific binding of the primary antibody. HAS3 (goat polyclonal antihuman antibody, Santa Cruz Biotechnology, Inc., CA, USA) was diluted 1:50 with antibody diluent (Dako North America, Inc., CA, USA) and applied to the sections, followed by standstill overnight at $4^{\circ} \mathrm{C}$. As secondary antibodies, polyclonal rabbit anti-goat immunoglobulins/ HRP (Dako Cytomation, Glostrup, Denmark) were used for HAS3, and were allowed to react for $45 \mathrm{~min}$ at room temperature. 3,3'diaminobenzidine (DAB Reagent Set, KPL, Gaithersburg, MD, USA) and Mayer's hematoxylin (Muto Pure Chemicals Ltd., Tokyo, Japan) were used for coloring. The negative controls were subjected to the same protocol except for the treatment with PBS instead of the primary antibody.

Each slide was analyzed by two independent observers under a light microscope (Nikon, Tokyo, Japan). Each figure was photographed with a digital camera (Nikon, Tokyo, Japan). The results were evaluated semiquantitatively on four scales: no expression (-); weak expression (+/-); moderate expression (+); and high expression (++). The HAS3 staining scales were analyzed on the disc.

\section{RT-PCR of the cultured cells under normoxia or hypoxia, stimulation with or without IL-1 $\beta$}

The total RNA from the cultured disc cells was isolated using an RNeasy® Mini Kit (Qiagen, Gaithersburg, MD, USA). First-strand cDNA was synthesized from $1 \mu \mathrm{g}$ of total RNA using SuperScript ${ }^{\circledR}$ transcriptase (Invitrogen, Carlsbad, CA, USA). Reactions were primed with Oligo (dT) 12-18 primers and the total volume was $20 \mu \mathrm{L}$. RT-PCR was performed using the BIO-RAD iCycler iQ system (BioRad, Hercules, CA, USA). Reactions were performed in a total volume of $50 \mu \mathrm{L}$ using $\mathrm{iQ}$ SYBR Green Supermix (BioRad); $0.5 \mu \mathrm{L}$ of cDNA sample was used as template. Cycling was started with an activation step at $95^{\circ} \mathrm{C}$ for $3 \mathrm{~min}$, the amplification program repeated 45 times (denatura- tion: $95^{\circ} \mathrm{C}$ for $15 \mathrm{~s}$; annealing: $60^{\circ} \mathrm{C}$ for $30 \mathrm{~s}$; extension: $72^{\circ} \mathrm{C}$ for $30 \mathrm{~s}$ ) with fluorescence measurement at $72^{\circ} \mathrm{C}$. All samples were run in triplicate for the internal control (18S rRNA: sense 5'-GTTGGTGGAGCGATTTGTCT-3' and antisense 5'-GGCCTCACTAAACCATCCAA-3') and the target gene (HAS3: sense 5'GAGCGGGCCTGCCAGTCCTACTT-3' and antisense 5'-AGCCAAGGCTCAGGACTCGGTT-3') on the same plate. The fluorescence threshold value was calculated using the $\mathrm{iCycle} \mathrm{iQ}$ system software version 3.0A. To confirm amplification specificity, the PCR products from each primer pair were subjected to a melting curve analysis. Real-time PCR efficiencies for each reaction were calculated using the formula: Efficiency $(E)=10^{[-1 / 1 / \text { lope }]}$, from the slope values given in the iCycle iQ system software. The $\Delta^{\mathrm{Ct}}$ values for the reference gene (18S rRNA) and the target gene were calculated by subtracting the experiment group (normoxia+IL-1, hypoxia and hypoxia+IL-1 $\beta$ ) from the control (normoxia). The mathematical model presented by Pfaffl was used to determine the relative quantification of the target gene in comparison to the reference gene. The relative expression ratio $(R)$ of the target gene was calculated based on $E$ and the $\Delta^{\mathrm{Ct}}$ of the experiment group versus the control, and expressed in comparison to $18 \mathrm{~S}$ rRNA.

\section{Statistical analysis}

Three independent experiments involving separate cell capture, RNA extraction and reverse transcription were performed. All values were expressed as the means of three experiments \pm S.D. Statistical significance was evaluated by multiple-comparison tests (Tukey-Kramer). A P-value less than 0.01 was considered as significant.

Table 1. Clinical and immunohistochemical data of the patients.

\begin{tabular}{|c|c|c|c|c|c|}
\hline Sample no. & Sex & Age (Years) & Diagnosis & Displacement of TMJ disc & Detection of HAS3 expression \\
\hline 1 & Female & 58 & Internal derangement & + & + \\
\hline 2 & Male & 64 & Internal derangement & + & + \\
\hline 3 & Female & 24 & Internal derangement & + & + \\
\hline 4 & Female & 52 & Internal derangement & + & + \\
\hline 5 & Female & 70 & Internal derangement & + & ++ \\
\hline 6 & Female & 53 & Internal derangement & + & + \\
\hline 7 & Female & 65 & Internal derangement & + & + \\
\hline 8 & Female & 36 & Internal derangement & + & ++ \\
\hline 9 & Female & 29 & Internal derangement & + & + \\
\hline 10 & Male & 36 & Internal derangement & + & ++ \\
\hline 11 & Female & 36 & Internal derangement & + & + \\
\hline 12 & Female & 72 & Internal derangement & + & ++ \\
\hline 13 & Female & 61 & Autopsy sample (control) & - & $+/-$ \\
\hline 14 & Female & 70 & Autopsy sample (control) & - & - \\
\hline 15 & Female & 48 & Autopsy sample (control) & - & $+/-$ \\
\hline
\end{tabular}




\section{Results}

The degree of temporomandibular joint disc degeneration

Three control specimens revealed no TMJ disc degeneration. Twelve discs with TMJ ID had severe grade of degeneration. There were peculiar to tears, splitting, fatty degeneration and chondroid metaplasia.

\section{HAS3 immunohistochemistry in the temporomandibular joint discs}

In all discs we identified fibroblast-like cells, fibrochondrocytes, without a pericellular halo; and chondrocyte-like cells with rounded nuclei surrounded by a large halo. ${ }^{20}$ In normal TMJ

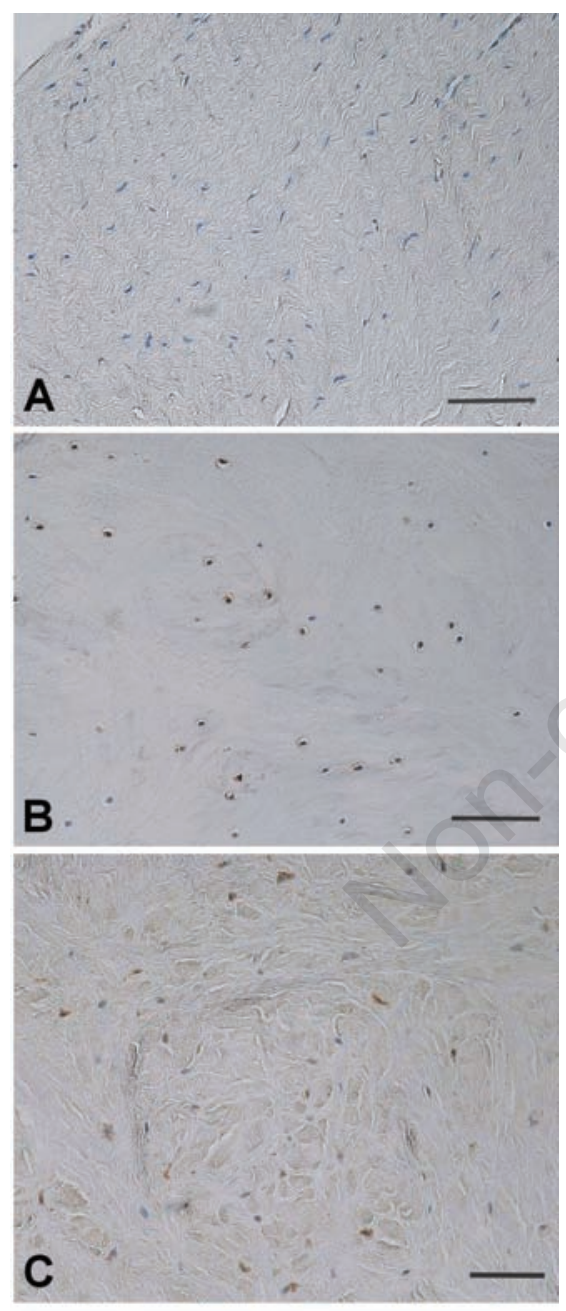

Figure 1. Immunohistochemical staining for HAS3. Panel A, negative staining for HAS3 in a normal disc. Panel B, moderate staining for HAS3 in a deformed disc. Chondrocyte-like cells are positive reaction. Panel C, moderate staining for HAS3 in a deformed disc. Fibrochondrocytes and chondrocyte-like cells are positive reaction. Scale bars: $100 \mu \mathrm{m}$. discs, the patterns of immunostaining for HAS3 were almost identical; no immunoreaction was observed in fibroblast-like cells and fibrochondrocytes. (Figure $1 \mathrm{~A}$ ). Some chondrocyte-like cells showed a weak staining.

In dysfunctional TMJ discs, moderate to strong immunostaining of chondrocyte-like cells were observed in all the twelve discs (Figure $1 \mathrm{~B}$ ); no immunolabeling of fibroblastlike cells and weak to moderate immunostaining of fibrochondrocytes was seen in the some cases (Figure $1 \mathrm{C}$ ). In the highest severely damaged disc, chondrocyte-like cells around the area of tears were strongly positive reaction. (Figure $2 \mathrm{~A}, \mathrm{~B}$ ).

\section{Effect of stimulation with IL-1 $\beta$ and of hypoxia on the expression of HAS3 mRNA in the cultured human temporomandibular joint disc cells}

The expression of HAS3 mRNA was significantly enhanced by stimulation with IL-1 $\beta$ alone and also by the combination of hypoxia and stimulation with IL-1 $\beta$. The quantity of HAS3 mRNA was compared with a control group by real-time PCR, and showed a 204 -fold increase at $3 \mathrm{~h}$, a 26 -fold increase at $6 \mathrm{~h}, \mathrm{a} 2.5$ fold increase at $12 \mathrm{~h}$ and a 32 -fold increase at $24 \mathrm{~h}$ under the combination of hypoxia and stimulation with IL-1 $\beta$. The expression of HAS3 mRNA was significantly enhanced at $3 \mathrm{~h}$ and 24
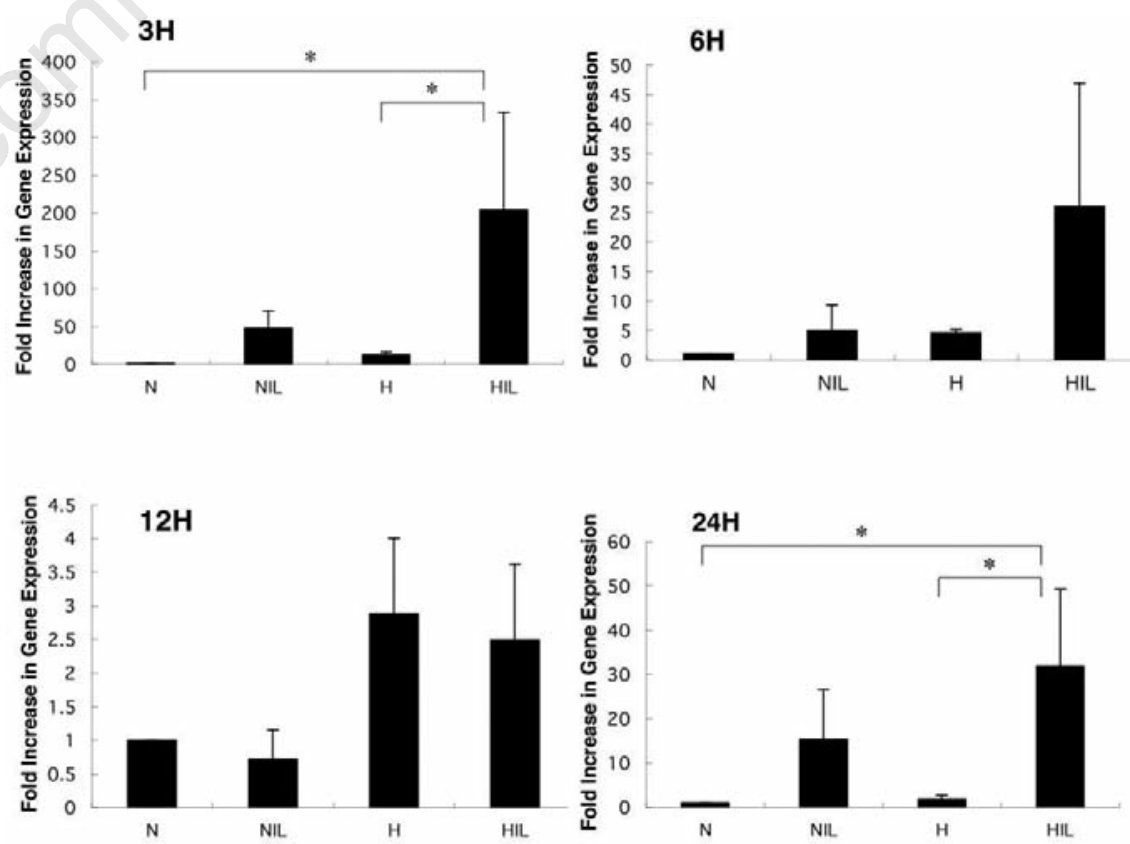

Figure 3. Effect of hypoxia and interleukin-1 $\beta$ on gene expression of HAS3 (RT-PCR). $\mathrm{N}$, normoxia; NIL, normoxia + interleukin-1 $\beta$; H, hypoxia; HIL, hypoxia + interleukin1 $\beta$. Asterisks denote significant differences $(P<0.01)$.

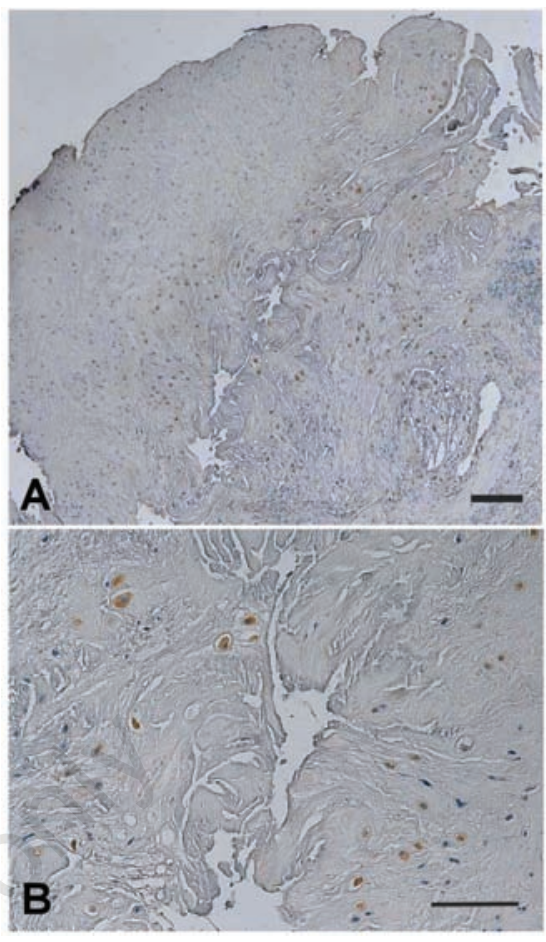

Figure 2. Immunohistochemical staining for HAS3 around tears. (A) TMJ disc with tears. HAS3 was strongly expressed in chondrocyte-like cells around tears. (B) close-up of A: Chondrocyte-like cells are strongly positive reaction. Scale bars: 100 $\mu \mathrm{m}$. 
h (control: hypoxia + IL-1 $\beta, \mathrm{P}<0.01$; hypoxia: hypoxia + IL-1 $\beta, \mathrm{P}<0.01$ ) (Figure 3 ). From these results, we concluded that the expression of HAS3 mRNA was up regulated in cultured human TMJ disc cells under the combination of hypoxia and stimulation with IL-1 $\beta$.

\section{Discussion}

It is confirmed that the expression of HAS3 up regulated under inflammation in synovial tissues in TMJ, ${ }^{21}$ but is not clear yet in the TMJ disc. In this study, we demonstrated using immunohistochemistry that HAS3 was detected in the pathological disc of the TMJ ID. The expression of HAS3 mRNA in human TMJ disc cells was significantly increased under hypoxia with the addition of IL-1 $\beta$. This result was consistent with the report, in which the expression of HAS3 is up regulated in pathological conditions. ${ }^{8}$

Immunohistochemically, this study demonstrated the presence of HAS3 in chondrocytelike cells both in normal and deformed TMJ discs. Immunohistochemical staining of deformed TMJ discs with ID showed strong expression of HAS3 in chondrocyte-like cells. Positive immunostaining was observed around tears and inside of deformed TMJ discs. This result might agree with a previous report that failure of proteoglycan monomers to form stable interactions with HA may be an important feature of the mechanisms underlying degenerative joint disease..$^{22}$ In degree of TMJ disc degeneration, Leonardi et al. proposed that three items are taken into account during the design of their disc degeneration score system, i.e. collagen bundle integrity or damage, degree of neo-vascularization and non specific degenerative changes: i.e. fatty degeneration, calcified areas, hyalinization (fibrosis), and chondroid metaplasia. ${ }^{18}$ In this study, twelve discs with TMJ ID showed a severe grade of degeneration. However, HAS3 expression patterns had no relationship to the grading score.

The TMJ disc is a tissue without blood vessels, and it is possible that it shows a similar oxygen concentration gradient to that of articular cartilage. Articular cartilage is a physiologically hypoxic tissue with oxygen gradients ranging between $6 \%$ and $1 \%$ from the surface layer of cartilage to the deep layer; ${ }^{23}$ therefore, it is possible that the oxygen partial pressure decreases under pathological conditions such as in TMJ disorders (TMJDs). In fact, Nitzan reveals that ischemia-reperfusion injury in TMJDs patients causes a hypoxic condition. ${ }^{12}$ When hydrostatic pressure in the joint capsule approaches $200 \mathrm{mg} \mathrm{Hg}$ by clenching, the hydrostatic pressure of the capillary ending is exceeded. Consequently, blood flow is interrupted temporarily and tissue hypoxia occurs. Therefore, in this study we used a low oxygen incubator to reproduce low oxygen conditions in vitro. Cells have a system which can detect a decrease in oxygen partial pressure and it is controlled by hypoxia inducible factor-1 (HIF1). ${ }^{24}$ It has been shown that HIF-1 greatly increases among patients with rheumatoid arthritis (RA) or OA when compared with a healthy control group. ${ }^{25}$ Wiesener indicates that HIF-1 becomes stabilized at oxygen concentrations below $3 \%{ }^{26}$ Taking these results into account, we set the oxygen concentration in this study at $2 \%$. It is well established that IL-1 $\beta$ is an inflammatory cytokine critically important for the pathogenesis of joint injury. IL-1 $\beta$ is produced by a number of different cell types, including macrophages and synovial cells. Suzuki et al. have identified a correlation between the levels of IL-1 $\beta$ in the synovium and both the degree of pain and the extent of clinical synovitis. ${ }^{27}$ Kubota et al. reported that synovial fluid levels of IL-1 $\beta$ in patients with ID or OA were greater than levels in fluid from 15 asymptomatic joints. ${ }^{28}$ In addition, the concentration of IL- $1 \beta$ was set at $1 \mathrm{ng} / \mathrm{mL}$, since a maximum of $1 \mathrm{ng} / \mathrm{mL}$ of IL- $1 \beta$ was detected in the synovial fluid of TMJDs patients. ${ }^{13}$ Realtime RT-PCR showed that expression of HAS3 was significantly increased in the presence of IL-1 $\beta$ in comparison with the control, with peaks at both normal and hypoxic conditions at $3 \mathrm{~h}$. This result was consistent with a report which found that IL-1 $\beta$ increased expression of HAS3. ${ }^{29}$ Our findings confirm that IL-1 $\beta$ enhances HAS3 mRNA expression in TMJ disc cells. Furthermore, the expression of HAS3 mRNA was significantly induced with IL-1 $\beta$ in hypoxic conditions. Hypoxia is reported to increase IL-1 $\beta$ in cultured articular chondrocytes. ${ }^{30}$ Repeated hypoxic conditions are caused by excessive mechanical stress in a diseased TMJ. In addition, hypoxia/reoxygenation induces the activation of NF- $\mathrm{B}$ in articular chondrocytes. ${ }^{30}$ The activation of NF- $\kappa \mathrm{B}$ is involved in induction of gene expression, which encodes inflammatory cytokines including TNF- $\alpha$, IL-1 $\beta$, and IL- 8 . $^{31}$ Thus, we conclude that HAS3 could be up regulated by a low dose of IL-1 $\beta$ induced by hypoxia/reoxygenation, which is caused by repeated mechanical stress.

This study has showed that HAS3 is increased with degeneration of the disc. Hypoxia and IL-1 $\beta$ synergistically enhanced HAS3 expression in cultured TMJ disc cells. Strong expression of HAS3 was therefore confirmed in the pathological phase of deformed discs with ID. In conclusion, we suggest that HAS3 is related to the pathological changes of human TMJ discs affected by ID.

\section{References}

1. Loreto C, Almeida LE, Migliore MR, Caltabiano M, Leonardi R. TRAIL, DR5 and caspase 3-dependent apoptosis in vessels of diseased human temporomandibular joint disc. An immunohistochemical study. Eur J Histochem 2010;54:183-7.

2. Fujita S, lizuka T, Dauber W. Localization of keratan sulphate and chondroitin-6-sulphate on the anteriorly displaced human temporomandibular joint disc--histological and immunohistochemical analysis. J Oral Rehabil 2001;28:962-70.

3. Leonardi R, Loreto C, Barbato E, Polimeni A, Caltabiano R, Lo Muzio L. A histochemical survey of the human temporomandibular joint disc of patients with internal derangement without reduction. $\mathrm{J}$ Craniofac Surg 2007;18:1429-33.

4. Laurent TC, Fraser JR. Hyarulonan. FASEB J 1992;6:2397-404.

5. Jacobson A, Brinck J, Briskin MJ, Spicer AP, Heldin P. Expression of human hyaluronan synthases in response to external stimuli. Biochem J 2000;348:2935 .

6. Itano N, Kimata K. Molecular cloning of human hyaluronan synthase. Biochem Biophys Res Commun 1996;222:816-20.

7. Itano N, Sawai T, Yoshida M, Lenas P, Yamada Y, Imagawa M, et al. Three isoforms of mammalian hyaluronan synthases have distinct enzymatic properties. J Biol Chem 1999;274:25085-92.

8. Oguchi T, Ishiguro N. Differential stimulation of three forms of hyaluronan synthase by TGF-beta, IL-1beta, and TNF-alpha. Connect Tissue Res 2004;45:197-205.

9. Sanders B. Arthroscopic surgery of the temporomandibular joint: treatment of internal derangement with persistent closed lock. Oral Surg Oral Med Oral Pathol 1986;62: 361-72.

10. McCain JP, Sanders B, Koslin MG, Quinn JD, Peters P, Indresano T. Temporomandibular joint arthroscopy: a 6-year multicenter retrospective study of 4,831 joints. J Oral Maxillofac Surg 1992;50:92630 .

11. Milam SB, Schmitz JP. Molecular biology of temporomandibular joint disorders: proposed mechanisms of disease. J Oral Maxillofac Surg 1995;53:1448-54.

12. Nitzan DW. Intraarticular pressure in the functioning human temporomandibular joint and its alteration by uniform elevation of the occlusal plane. J Oral Maxillofac Surg 1994;52:671-9.

13. Kubota E, Kubota T, Matsumoto J, Shibata T, Murakami K.I. Synovial fluid cytokines and proteinases as markers of temporo- 
mandibular joint disease. J Oral Maxillofac Surg 1998;56:192-8.

14. Takahashi T, Kondoh T, Fukuda M, Yamazaki Y, Toyosaki T, Suzuki R. Proinflammatory cytokines detectable in synovial fluids from patients with temporomandibular disorders. Oral Surg Oral Med Oral Pathol Oral Radiol Endod 1998;85:135-41.

15. Shinoda C, Takaku S. Interleukin-1beta, interleukin-6, and tissue inhibitor of metalloproteinase- 1 in the synovial fluid of the temporomandibular joint with respect to cartilage destruction. Oral Dis 2000;6:38390.

16. Kaneyama K, Segami N, Nishimura M, Suzuki T, Sato J. Importance of proinflammatory cytokines in synovial fluid from 121 joints with temporomandibular disorders. Br J Oral Maxillofac Surg 2002;40:418-23.

17. Vincenti MP, Brinckerhoff CE. Early response genes induced in chondrocytes stimulated with the inflammatory cytokine interleukin-1beta. Arthritis Res 2001;3: 381-8.

18. Leonardi R, Rusu MC, Loreto C. Temporomandibular joint disc: a proposed histopathological degeneration grading score system. Histol Histopathol 2010;25:1117-22.

19. Matsumoto T, Tojyo I, Kiga N, Hiraishi Y, Fujita S. Expression of ADAMTS-5 in deformed human temporomandibular joint discs. Histol Histopathol 2008;23:1485-93.
20. Kiga N, Tojyo I, Matsumoto T, Hiraishi Y, Shinohara Y, Fujita S. Expression of lumican in the articular disc of the human temporomandibular joint. Eur J Histochem 2010;54:152-7.

21. Li J, Long X, Ke J, Meng QG, Lee WC, Doocey JM, et al. Regulation of HAS expression in human synovial lining cells of TMJ by IL-1beta. Arch Oral Biol 2008;53: 60-5.

22. Milam SB, Klebe RJ, Triplett RG, Herbert D. Characterization of the extracellular matrix of the primate temporomandibular joint. J Oral Maxillofac Surg 1991;49:38191.

23. Cernanec J, Guilak F, Weinberg JB, Pisetsky DS, Fermor B. Influence of hypoxia and reoxygenation on cytokine-induced production of proinflammatory mediators in articular cartilage. Arthritis Rheum 2002;46:968-75.

24. Semenza GL. Hypoxia-inducible factor 1: oxygen homeostasis and disease pathophysiology. Trends Mol Med 2001;7:345-50.

25. Giatromanolaki A, Sivridis E, Maltezos E, Athanassou N, Papazoglou D, Gatter KC, et al. Upregulated hypoxia inducible factor1alpha and -2alpha pathway in rheumatoid arthritis and osteoarthritis. Arthritis Res Ther 2003;5:R193-201.

26. Wiesener MS, Turley H, Allen WE, Willam C, Eckardt KU, Talks KL, et al. Induction of endothelial PAS domain protein-1 by hypoxia: characterization and comparison with hypoxia-inducible factor-1 alpha. Blood 1998;92:2260-8.

27. Suzuki T, Segami N, Kaneyama K, Nishimura M, Nojima T. Specific expression of interleukin-1 beta in temporomandibular joints with internal derangement: correlation with clinical findings. Oral Surg Oral Med Oral Pathol Oral Radiol Endod 1999;88:413-7.

28. Kubota E, Imamura H, Kubota T, Shibata T, Murakami K. Interleukin 1 beta and stromelysin (MMP3) activity of synovial fluid as possible markers of osteoarthritis in the temporomandibular joint. $\mathrm{J}$ Oral Maxillofac Surg 1997;55:20-7.

29. Tanimoto K, Ohno S, Fujimoto K, Honda K, Ijuin C, Tanaka N, et al. Proinflammatory cytokines regulate the gene expression of hyaluronic acid synthetase in cultured rabbit synovial membrane cells. Connect Tissue Res 2001;42:187-95.

30. Martin G, Andriamanalijaona R, Grassel S, Dreier R, Mathy-Hartert M, Bogdanowicz $\mathrm{P}$, et al. Effect of hypoxia and reoxygenation on gene expression and response to interleukin-1 in cultured articular chondrocytes. Arthritis Rheum 2004;50:354960.

31. Han MK, Kim JS, Park BH, Kim JR, Hwang BY, Lee HY, et al. NF-kappaB-dependent lymphocyte hyperadhesiveness to synovial fibroblasts by hypoxia and reoxygenation: potential role in rheumatoid arthritis. J Leukoc Biol 2003;73:525-9. 